\title{
SOBRE POESIA INDÍGENA: O CASO DO POEMA "AY KAKUYRI TAMA (EU MORO NA CIDADE)”, DE MÁRCIA WAYNA KAMBEBA
}

\author{
ABOUT INDIGENOUS POETRY: THE CASE OF THE POEM "AY KAKUYRI \\ TAMA (I LIVE IN THE CITY)", BY MÁRCIA WAYNA KAMBEBA
}

\author{
Walace Rodrigues ${ }^{11}$ \\ Delma Pacheco Sicsu 22 \\ José Benedito dos Santos ${ }^{33}$ \\ Júpiter Koroá Lima Cunha ${ }^{44}$ \\ Maria das Dores Pereira Santos 55 \\ Samara Laiz Silva Machado 66 \\ Sophie Celine Sylvie Guerin Mateus ${ }^{77}$
}

Resumo: Este artigo nasceu de diferentes leituras analíticas por meio das quais se tentou apresentar possíveis interpretações do poema "Ay Kakuyri Tama (Eu moro na cidade)", da autora indígena amazonense Márcia Kambeba. Esta pesquisa coloca-se como teórica e de cunho bibliográfico. Julgamos que este tema seja relevante para pensar os diferentes tipos de literaturas emergentes na sociedade atual, a exemplo da literatura indígena. Como resultado, foi possível observar que a poesia indígena de Márcia Kambeba nos revela ter um forte aporte na memória, na oralidade, na afirmação da identidade indígena, entre outros pontos, dando voz às mulheres/poetas indígenas e reafirmando a importância de seus territórios sociais.

Palavras-chave: poesia; texto literário; cultura.

1 Doutor em Humanidades pela Universiteit Leiden (Países Baixos). Pós-doutor pela Universidade de Brasília POSLIT/UnB. Professor Adjunto da Universidade Federal do Tocantins - UFT, campus de Araguaína. Docente do Programa de Pós-Graduação em Demandas Populares e Dinâmicas Regionais (PPGDire) e da Pós-Graduação em Ensino de Língua e Literatura (PPGL). Pesquisador no grupo de pesquisa Grupo de Estudos do Sentido Tocantins - GESTO e no Grupo de Estudos e Pesquisa em Demandas Populares e Dinâmicas Regionais, ambos da Universidade Federal do Tocantins - UFT - CAPES/CNPq. ORCID: orcid.org/0000-0002-9082-5203

2 Doutoranda da da Pós-Graduação em Literatura da Universidade de Brasília - UnB. Professora da Universidade do Estado do Amazonas (UEA). E-mail: delmasicsu@bol.com.br ORCID: orcid/org/0000-0002-1828-289X

3 Doutorando da Pós-Graduação em Literatura da Universidade de Brasília - UnB. Professor da SEDUC/AM. Email: profbenesantos@hotmail.com ORCID: orcid/org/0000-0002-4298-8462

4 Mestrando da Pós-Graduação em Literatura da Universidade de Brasília - UnB. E-mail: jupiterkoroa@gmail.com ORCID: orcid/org/0000-0003-3408-2553

5 Doutoranda da Pós-Graduação em Literatura da Universidade de Brasília - UnB. Professora da Universidade do Estado da Bahia (UNEB), campus VIII, Paulo Afonso. E-mail: dorisantos68@ gmail.com ORCID: orcid/org/00000002-9035-3381

6 Doutoranda da Pós-Graduação em Literatura da Universidade de Brasília - UnB. E-mail: sliz.slm@gmail.com ORCID: orcid/org/0000-0002-5676-2704

7 Doutoranda da Pós-Graduação em Literatura da Universidade de Brasília - UnB. E-mail: sophieguerinmateus@gmail.com; ORCID:orcid.org/0000-0002-2620-1519 
Abstract: This paper was created from possible interpretations of the poem "Ay Kakuyri Tama (I live in the city)", by the indigenous Amazonian author Márcia Kambeba. This research is presented as a theoretical one and of a bibliographical nature. We believe that this theme is relevant to think about the different types of literatures emerging in today's society, as well as indigenous literature. The indigenous poetry of Márcia Kambeba reveals to us a strong dependency on memory and orality, the affirmation of indigenous identity, among other points, giving voice to indigenous women/poets and reaffirming the importance of their social territories.

Keywords: poetry; literary text; culture.

\section{Introdução}

Este texto resulta de discussões teóricas realizadas na disciplina “Tópicos Especiais em Literatura Brasileira", ofertada no Programa de Doutorado em Literatura (Póslit) da Universidade de Brasília - UnB, durante o primeiro semestre de 2019. Na ocasião, foi possível observar diferentes aspectos criativos relacionados aos processos de elaboração das artes indígenas brasileiras, tais como cerâmica, plumárias e outras expressões artístico-culturais, como a literatura.

Para a discussão proposta neste artigo, circunscrita à arte literária, foi tomado como corpus o poema "Ay Kakuyri Tama (Eu moro na cidade)", da autora indígena amazonense Márcia Wayna Kambeba. Tal poema está na antologia homônima, e é o primeiro texto na ordem de organização de tal publicação.

A base metodológica desta pesquisa é exploratória e de caráter qualitativo, tendo como aporte uma bibliografia que prioriza conceitos da antropologia, da arte e da literatura, tomados em diálogo interdisciplinar, como forma de tentar enriquecer a leitura crítico-analítica do poema com múltiplas interpretações possíveis.

\section{Um texto literário indígena: considerações sobre o poema "Ay Kakuyri Tama (Eu moro na cidade)"}

Não podemos nos esquecer que o homem narra. Narrar é uma experiência enraizada na existência humana. É uma prática humana universal, trans-histórica, pancultural. Narrar é um 
metacódigo. Vivemos mediante narrações todos os povos, culturas, nações e civilizações se constituíram narrando. Construímos nossa biografia e nossa identidade pessoal narrando. Nossas vidas são acontecimentos narrativos. O acontecer humano é uma sucessão temporal e causal. Vivemos as nossas relações conosco mesmos e com os outros narrando. Nossa vida é uma teia de narrativas na qual estamos enredados (MOTA, 2013, p. 17).

Nesse sentido, a literatura indígena brasileira é um fenômeno que causa bastante interesse hoje em dia, pois são vários são os indígenas que tomam para si a escrita, buscando nela uma forma de representação e de luta dentro das sociedades ocidentais. No Brasil, essa literatura, que segue modelos ocidentais, tem revelado vários autores indígenas de grande qualidade literária, entre eles Daniel Munduruku, Eliane Potiguara, Graça Graúna, entre tantos outros.

Tomando tal produção pelo viés da cultura, chegamos ao termo "oralitura", cunhado por Paul Zumthor, o qual designa bem uma das principais características dessa literatura: sua vinculação intrínseca à oralidade desses povos. Assim, podemos dizer que a literatura indígena atual tem suas construções fortemente alicerçadas na literatura oral. Daniel Munduruku nos esclarece essa questão:

O papel da literatura indígena é, portanto, ser portadora da boa notícia do (re)encontro. Ela não destrói a memória na medida em que a reforça e acrescenta ao repertorio tradicional outros acontecimentos e fatos que atualizam o pensar ancestral. Há um fio muito tênue entre oralidade e escrita, disso não se duvida. Alguns querem transformar este fio numa ruptura. Prefiro pensar numa complementação. Não se pode achar que a memória não se atualiza. É preciso notar que ela - a memória - está buscando dominar novas tecnologias para se manter viva. A escrita é uma dessas técnicas, mas há também o vídeo, o museu, os festivais, as apresentações culturais, a internet com suas variantes, o rádio e a TV. Ninguém duvida que cada uma delas é importante, mas poucos são capazes de perceber que é também uma forma contemporânea de a cultura ancestral se mostrar viva e fundamental para os dias atuais. Pensar a Literatura Indígena é pensar no movimento que a memória faz para apreender as possibilidades de mover-se num tempo que a nega e que nega os povos que a afirmam. A escrita indígena é a afirmação da oralidade. (MUNDURUKU, 2008, $\mathrm{s} / \mathrm{p})$

No âmbito dessa "afirmação da oralidade", um desses escritores indígenas é Márcia Wayna Kambeba. Seu nome de registro civil é Márcia Vieira da Silva e é nascida na aldeia Tikuna, no Alto Solimões. Ela é mestra em Geografia pela Universidade Federal do Amazonas 
- UFAM e hoje coloca-se como uma importante representante da música, literatura e cultura

indígenas no Brasil. Reside em Castanhal, no Pará, e, de lá, parte para muitos lugares mundo afora para valorizar a cultura dos povos indígenas através de suas performances musicais e poéticas. Seu povo é Omágua-Kambeba, etnia amazonense conhecida como sendo de grandes guerreiros no passado, e que teve suas tradições de achatar a cabeça (eram conhecidos como cabeça chata) deixada de lado com o passar dos tempos.

Sobre a luta diária da referida autora pela preservação e divulgação da cultura indígena, ela própria nos diz:

\begin{abstract}
Diante desse novo cenário que surge a partir das ações políticas empreendidas pelo povo Omágua/Kambeba, em um processo de reorganização e instrumentalização das demandas e reivindicações por seus direitos, incluindo o território que, por conseguinte, se estende a busca por autonomia e livre determinação diante das decisões que envolvem a sociedade Omágua/Kambeba. A luta deste povo não se resume apenas em defender seus limites territoriais, seus membros lutam também por uma forma de existência, presente no modo diferente de viver, ver, sentir, pensar, agir e de seguir construindo seus direitos. As reivindicações estendem-se, ainda, à luta por uma organização no trabalho pedagógico, que tem como objetivo o ensino da língua materna. A língua Omágua/Kambeba classifica-se como "uma língua em perigo", pelo fato de apresentar sinal de declínio na sua transmissão de uma geração a outra. Por isso, a necessidade de se elaborar um dicionário com palavras e frases do cotidiano dos Omágua/Kambeba. Entende-se que novos usos apontam mais para um processo de transformação do que para um processo de extinção. (SILVA, 2012, p. 165)
\end{abstract}

Língua, luta, resistência, identidade, territorializar e se desterritorializar, memórias, tradição e ser indígena na cidade constituem-se, então, alguns dos temas vitais recorrentes na poesia de Márcia Kambeba. Para a análise que pretendemos apresentar neste artigo, destacamos alguns aspectos formais e expressivos do poema "Ay Kakuyri Tama (Eu moro na cidade)", disponível no livro homônimo publicado em 2013:

\title{
AY KAKUYRI TAMA \\ (Eu Moro na Cidade)
}

Ay kakuyri tama.

Ynua tama verano y tana rytama.

Ruaia manuta tana cultura ymimiua,

Sany may-tini, iapã iapuraxi tanu ritual.

Tradução:

Eu moro na cidade

Esta cidade também é nossa aldeia, 
Não apagamos nossa cultura ancestral, Vem homem branco, vamos dançar nosso ritual.

Nasci na Uka sagrada,

Na mata por tempos vivi,

$\mathrm{Na}$ terra dos povos indígenas,

Sou Wayna, filha da mãe Aracy.

Minha casa era feita de palha,

Simples, na aldeia cresci

$\mathrm{Na}$ lembrança que trago agora,

De um lugar que eu nunca esqueci.

Meu canto era bem diferente,

Cantava na língua Tupi,

Hoje, meu canto guerreiro,

Se une aos Kambeba, aos Tembé, aos Guarani.

Hoje, no mundo em que vivo,

Minha selva, em pedra se tornou,

Não tenho a calma de outrora,

Minha rotina também já mudou.

Em convívio com a sociedade,

Minha cara de "índia" não se transformou,

Posso ser quem tu és,

Sem perder a essência que sou,

Mantenho meu ser indígena,

Na minha Identidade,

Falando da importância do meu povo,

Mesmo vivendo na cidade.

Por uma perspectiva cultural do olhar brasileiro sobre o indígena, podemos ver que na literatura brasileira, desde o século XVIII, o indianismo é uma das temáticas mais importantes. Tal corrente estética foi muito utilizada no Arcadismo (protagonismo indígena) e no Romantismo (representação do Bom selvagem). Indígenas foram retratados em obras como: “O Uraguay” (Basílio da Gama, 1769), “Caramuru” (Santa Rita Durão, 1781), “O Guarani” (1857), "Iracema" (1865), “Ubirajara” (1874), entre outras. Estas são algumas das obras escritas por autores não indígenas que exaltaram o índio, tomando este como representação primordial da nossa identidade. No entanto, essas obras representavam os indígenas como sujeitos submissos e ingênuos, contribuindo, assim, para uma representação equivocada sobre a presença do índio na sociedade brasileira. Para Eni Orlandi, os indígenas sempre foram colocados na história brasileira como pessoas sem voz ou "falando" através de outros:

Com efeito, o índio não fala na história (os textos que são tomados como documentos) do Brasil. Ele não fala, mas são falados pelos missionários, pelos cientistas, pelos políticos [...] Eles falam do Índio para que ele não signifique fora de certos sentidos necessários para a construção de uma identidade brasileira determinada em que o Índio não conta. Trata-se da construção de sentidos que servem, sobretudo, à 
instituição das relações colonialistas entre os países europeus e o Novo Mundo (ORLANDI, 1993, p. 59).

Na década de 1980, Tõrãmu Kẽhríri (Luiz Gomes Lana), indígena da etnia Desana, publicou a obra "Antes o mundo não existia: mitologia dos antigos Desana-Kehíripõrã", considerada a primeira obra escrita por um indígena. Após 500 anos da colonização europeia acontecida no Brasil, um indígena expressava-se, através da literatura, sem intermediários. Porém, hoje em dia a situação dos indígenas sofre forte transformação, podendo ser compreendida a partir de três dimensões constitutivas de suas produções autorais:

Os índios que vivem nas grandes cidades e trilharam o mundo acadêmico. Há um segundo tipo, que manteve contato maior com a cidade sem a academia. E, o terceiro perfil de escritor-indígena é aquele que vive em sua comunidade e faz o resgate da oralidade dos mais velhos (SOUZA, 2009, p. 22)

Assim sendo, a escritora Márcia Kambeba, adotando como estratégia a narrativa das histórias orais dos Omágua/Kambeba, quebra "a conspiração do silêncio" que paira sobre a cultura indígena, além de retirar da invisibilidade os Omágua/Kambeba. Ela desconstrói a ideia de que o índio é um sujeito subalterno, porque escreve a partir do ponto de vista e do lugar de fala da mulher indígena, assumindo o papel de Griota, ao transportar a memória dos Omágua/Kambeba para o reino das palavras escritas.

A autora, como descendente dos primeiros habitantes do Brasil, ao trilhar o mundo da literatura, torna-se uma das vozes que emergem das margens da floresta e da Amazônia brasileira para resgatar a memória, a luta pela construção de uma identidade, além de desconstruir a ideia de que o indígena é um povo subalterno.

Para o também escritor indígena Daniel Munduruku:

[...] nossos escritos são literaturas, sim. E são indígenas, sim. Não há motivo para negar isso e menos ainda para partilhar com os escritores não indígenas o merecimento que nosso esforço tem conseguido em tão pouco tempo. Dizer que o que escrevemos é "apenas" literatura brasileira, é dividir com todos aqueles que escreveram, escrevem e escreverão coisas medíocres a respeito de nossa gente, um status que não foi construído por eles. Nossa literatura é indígena para que não se venha repetir que "somos os índios que deram certo" (MUNDURUKU, 2016, s/p)

A escritora indígena Márcia Kambeba, ao recolher as narrativas orais dos povos Omágua/Kambeba para sua inspiração e posterior inserção no suporte poesia/livro, quebra a "conspiração do silêncio" que paira sobre a cultura indígena para, então, construir uma visibilidade identitária e literária própria. 
Na apresentação da obra "Ay Kakuyri Tama (Eu moro na cidade)" (2013), o historiador Benedito Maciel, da Universidade Federal do Amazonas - UFAM, afirma que é um

Documento de vida que reúne coragem denúncia e esperança. Coragem, porque traz à tona problemas de identidade étnica do passado e do presente dos índios que desafiam permanentemente as relações interétnicas na Amazônia; denúncia, porque escancara o cinismo e o preconceito da sociedade brasileira contra os índios, especialmente, contra os "índios citadinos"; esperança porque não se perde na lamentação das perdas e nem se contenta com a aclamação de um 'passado heroico', mas rima agradável e sutilmente a dinâmica da vida indígena e a realidade social na Amazônia. É numa lição de vida e de cidadania. Mais uma resposta inteligente dos Kambeba ao mundo dos brancos. Enfim, é uma flecha que rasga o tempo da história e quebra o silêncio monstruoso que protege aqueles que se sentem vencedores. (KAMBEBA, 2013, p. 16)

Quando iniciamos a leitura do poema “Ay Kakuyri Tama (Eu moro na cidade)” que, conforme exposto, dá título ao livro, temos a sensação momentânea de que voltamos ao início da colonização brasileira, em particular da Amazônia, porque a escritora Márcia Kambeba discute, de forma poética, sobre desterritorialização, apagamento identitário e aculturação efetivada pelos europeus contra os povos indígenas brasileiros. Como disse o crítico Francisco Foot Hardman (2000, p. 11), para recuperar essas “memórias das ruínas, sejam as das paisagens passadas dessa Amazônia sublime, sejam próprias memórias de outras memórias e de outras vozes, alcançáveis apenas como fatos de ficção” faz-se necessário muita literatura indígena. De onde vem nossa necessidade de lembrar? Ou: por que a lembrança se impõe até mesmo quando não temos intenção de recordar? A aceitação dessa ideia nos remete à tese de Walter Benjamin (2000):

A memória não é um instrumento para a exploração do passado; é antes, o meio. É o meio onde se deu a vivência, assim como o solo é o meio sutil no qual as antigas cidades estão soterradas. Quem pretende se aproximar do próprio passado soterrado deve agir como o homem que escava (BENJAMIN, 2000, p. 239).

Nas sociedades ágrafas os Griots e Griotas "constituem-se como contadores e contadoras de histórias que são fundamentais para a permanência da humanidade: são como um acervo vivo de um povo. Carregam nos seus corpos histórias, lendas, feitos, canções, lições de vida de toda uma população, envoltos numa magia própria, específica dos que encantam com o corpo e com sua oralidade" (BRANDÃO, 2006, p. 36). Desse modo, a escritora Márcia Kambeba, ao resgatar o passado cultural de seu povo, quase apagado pela colonização europeia, escolhe a literatura enquanto estratégia de luta, em particular a poesia, para manufaturar as histórias dos Omágua/Kambeba como inscrição de objetos culturais orais no suporte livro. Como resultado 
desse processo, os registros escritos são uma possibilidade de perpetuar memórias, artefatos fundamentalmente importantes para um povo como uma história de tantas lutas como são os Omágua/Kambeba.

A presença do indígena como protagonista e, ao mesmo tempo, como escritor de sua cultura sugere a criação de um espaço de resistência cultural, mas também materializa a construção de um lugar de fala para os nativos da Amazônia na literatura brasileira contemporânea. Ou, como afirma Eni Orlandi, em “Terra à Vista” (1990, p. 56):

Esse processo de apagamento do índio da identidade cultural nacional tem sido escrupulosamente mantido durante séculos. E se produz pelos mecanismos mais variados, dos quais a linguagem, com violência simbólica que ela representa, é um dos mais eficazes [...] São, desde o começo, o alvo de um apagamento, não constituem nada em si. Esse é o seu estatuto histórico 'transparente' não consta. Há uma ruptura histórica pela qual passam do índio para o brasileiro através de um salto (ORLANDI, 1990, p. 56).

Também, na apresentação da obra “África(s), índios e negros” (2016), Ivaldo Marciano de França Lima afirma que:

[...] a categoria 'índios' não é isenta de problemas, e traz consigo visões diversas, tanto daqueles a quem este conceito se propõe a nomear, como dos que se dedicam às investigações sobre os primeiros. Há casos em que estes lugares estão marcados, mas há também os que borram as fronteiras, pois hoje são inúmeros os 'índios' que ingressam nas universidades e discorrem a partir de outros pontos de vista e lugares de fala [...] os índios como dotados de um olhar autônomo, protagonistas de sua própria história. Não seria demais afirmar que os índios fizeram escolhas, traçaram estratégias, insistiram em caminhos e teceram alianças. (LIMA et al, 2016, p. 25)

Ainda, como afirma Pollack:

[...] a memória é um fenômeno construído social e individualmente, quando se trata da memória herdada, podemos também dizer que há uma ligação fenomenológica muito estreita entre a memória e o sentimento de identidade. [...] É a imagem que uma pessoa adquire ao longo da vida referente a ela própria, a imagem que ela constrói e apresenta aos outros e a si própria, para acreditar na sua própria representação, mas também para ser percebida da maneira como quer ser percebida pelos outros. [...] Podemos, portanto, dizer que a memória é um elemento constituinte do sentimento de identidade, tanto individual como coletiva, na medida em que ela também é um fator extremamente importante do sentimento de continuidade e de coerência de uma pessoa ou de um grupo em sua reconstrução de si. (POLLACK, 1992, p. 204)

Assim, em seu poema "Ay Kakuyri Tama (Eu moro na cidade)", Márcia Kambeba trabalha a temática do intercâmbio cultural entre população indígena rural e população nãoindígena urbana, a partir de sua perspectiva de quem cresceu na aldeia e atualmente mora na cidade. 
Desde o título, e no decorrer de toda a obra, o poema apresenta uma característica muito interessante e que dialoga diretamente com o tema: é escrito no idioma Tupi e no idioma Português-BR, de forma concomitante. Algumas palavras são traduzidas, outras não. Isso nos remete ao processo de troca de conhecimento - e até mesmo, por que não?, adaptação - entre diferentes culturas. O idioma de um povo é um fator base nesse processo. A possibilidade da comunicação, em via dupla, é essencialmente facilitadora dessa dinâmica.

Para o leitor não-indígena pode haver um estranhamento ao não conhecer determinadas palavras do poema. Esse encontro é valioso ao nos permitir a reflexão sobre como se dá reciprocamente a vivência oposta: quando pessoas não-falantes de português se encontram na situação de compreender as palavras de um idioma que não dominam. A reflexão pode ir além: essa língua que, a muitos de nós, causa estranheza, poderia ser, na verdade, o nosso próprio idioma - uma vez que foi desenvolvida em território que chamamos de nacional. No entanto, a língua que temos como oficial veio de outro continente. Essas são questões que podem ser pensadas por várias vias.

O referido poema também desenvolve o fator de intercâmbio cultural, tanto ao apresentar a perspectiva indígena, quanto ao estender o convite ao homem branco para juntos "dançar nosso ritual". A abertura à troca nos convida também a revisitar a história do contato entre esses diferentes povos. Desde os convites que não foram feitos, aos que não foram aceitos, e aos que foram impostos. Assim como outras práticas, é notável como as trocas culturais podem acontecer de forma a acrescentar elementos simbólicos aos povos envolvidos, mas também de forma a subtrair.

Ainda no poema, a autora retoma, em diversas passagens, sua história e sua memória. Nesse caminhar, observamos a busca de um equilíbrio entre o fluxo de mudanças e a manutenção de sua essência. Fica evidente o entendimento sobre identidade cultural, sendo esta imutável em determinados aspectos, embora sujeita a interlocuções e interferências naturais do convívio diverso.

Pensando no contexto de globalização em que vivemos, estamos a todo momento consumindo diferentes culturas, e ainda assim nos mantemos brasileiros. Da mesma forma, não faz sentido quando se questiona a identidade de uma pessoa indígena a partir da perspectiva superficial advinda de um pré-conceito sobre o que torna uma pessoa indígena (como no caso do uso de roupas ocidentais, tecnologia de ponta, o local de moradia, entre outros usos e objetos). 
Também, para Selon Cuche, "cada identidade integra, de modo sintético, a pluralidade das referências identificatórias ligada à sua história" (2006, p. 148). O imigrante tem assim o que podemos chamar uma "identidade mista", já que possui referências da cultura dos pais e da cultura do país no qual está vivendo. No caso do indígena que se muda para a cidade, podemos também falar de identidade mista porque ele integra à sua identidade, formada pela vivência na sua aldeia, traços da identidade do lugar onde ele passa a viver.

Essa identidade mista aparece ao longo do poema "Ay Kakuyri Tama (Eu moro na cidade)” de Márcia Wayna Kambeba (2013, p. 23), em primeiro lugar, pelo uso das línguas tupi e portuguesa. Assim, o título e a primeira estrofe são escritos em Tupi e autotraduzidos em português.

No restante do corpo do poema, prevalece o registro em português, mas aparecem palavras em Tupi, como Uka, que significa casa, assim como nomes próprios como Wayna, Aracy e os nomes dos povos Omágua/Kambeba, Tembé e Guarani. Podemos observar que a palavra portuguesa ritual é usada na estrofe em tupi. Tal procedimento de criação sugere o reconhecimento de que a língua constitui uma parte importante de nossa visão de mundo, e esse recurso presente na escrita, pela mescla dos dois idiomas, parece representar o pertencimento de Márcia Wayna Kambeba às duas culturas.

Por meio desse bilinguismo que estrutura o poema, a poeta constrói uma ponte entre essas duas culturas que compõem agora sua identidade. Ela convida, por exemplo, o homem branco a dançar o ritual indígena. Mas, o seu lado indígena é mais presente, mais forte, é sua primeira referência, a da infância. Ela foi criada na aldeia, com os valores e a visão de mundo de seu povo. Quando fala de sua vida atual na cidade, sempre traça um vínculo com suas origens: a cidade é uma aldeia, uma selva de pedra, ela continua cantando, apesar desse canto ter-se modificado. Ela se transformou, perdeu um pouco de sua calma e mudou sua rotina, mas, apesar de incorporar novos traços, ela permanece uma índia, antes de tudo.

A conservação de sua identidade indígena se torna, assim, um combate fundamental para ela: "Não apagamos nossa cultura ancestral”. Sua história e sua família fazem parte do que ela é, e ela não pode (não quer) esquecer de onde vem. Vemos isso claramente em: "Minha cara de "índia" não se transformou, / Posso ser quem tu és, / Sem perder a essência que sou, / Mantenho meu ser indígena, / Na minha Identidade."

Outro aspecto relevante desse poema homônimo que abre a obra é a presença de imagens musicais como: "Meu canto era bem diferente, / Cantava na língua Tupi, /Hoje, meu canto guerreiro, / Se une aos Kambeba, aos Tembé, aos Guarani”. Consideramos relevante para a 
análise a junção de um poema subsequente, "Ser indígena - ser omágua”, pois nele destacamos um dos versos iniciais que retoma o tema do canto laudatório à etnia indígena e chama a atenção em sua abertura pelo seguinte verso: "Sou filha da selva, minha fala é Tupi" (p. 25). Essa estrutura temático-poética ecoa em viés intertextual os seguintes versos de I- Juca Pirama, poema romântico de autoria de Gonçalves Dias:

\author{
Sou filho das selvas, \\ Nas selvas cresci; \\ Guerreiros, descendo \\ Da tribo tupi. \\ Da tribo pujante, \\ Que agora anda errante \\ Por fado inconstante, \\ Guerreiros, nasci (DIAS, 2002, s/p)
}

Não obstante o reconhecimento desse entrecruzamento temático-formal com o romantismo brasileiro em sua vertente indianista, haja vista a forma compositiva similar obtida pela organização em versos curtos ritmados, inclusive parafrásticos enquanto tema, no qual os dois eu-líricos tangenciam proximidades culturais de um mesmo grupo - os tupis -, tal irmanação identitária unívoca é problematizada em favor da inclusão de outros grupos: "Cantava na língua Tupi, /Hoje, meu canto guerreiro, / Se une aos Kambeba, aos Tembé, aos Guarani”. Essa transmutação do isolamento belicoso em agregação ou recuperação do sentimento de pertencimento cultural sugere um processo de ampliação polifônica que pode ser iluminado pelos seguintes versos do segundo poema: “Que o nosso canto ecoe pelos ares como um grito de clamor a Tupã, em ritos sagrados, em templos erguidos, em todas as manhãs! ”. Notamos, na mudança do "eu" para "nosso canto", um movimento de resistência que atesta a inclusão da coletividade como paradigma de existência dos povos indígenas.

Ainda, tais procedimentos artístico-literários presentes no poema de Kabemba anunciam a instauração lírica da memória e recuperação da ancestralidade, bem como um certo diálogo com a voz da estética romântica indianista heróica, conforme exposto anteriormente, configurando o que Didi-Huberman, em sua análise da poética brechtiana, diz constituir um "lirismo de guerra" que:

[...] consiste em remontar a história, nos sentidos que essa expressão admite: remontar, isto é, nadar contra a corrente do rio, onde, no presente a história política quer nos levar; remontar, isto é, dispor todas as coisas trabalhando nas clivagens do tempo, desconstruindo-o (...) isso supõe inventar ritmos, escrever por cortes e por 
remontagens constantes; mas isso supõe, também ver a história se desenrolar diferentemente como uma crônica factual portadora de sentido, se não for de um télos (DIDI-HUBERMAN, 2017, p. 172)

A ideia desse "lirismo de guerra" foi pensada por Brecht como forma de apresentar uma imagem do exílio; porém, o corpus que analisamos bem pode acolher uma leitura por este ângulo interpretativo, afinal, qual termo melhor que exílio poderia explicitar de forma tão feliz o apagamento ou silenciamento histórico-cultural das artes indígenas? Ao assumir tal lugar de leitura, assumimos ao mesmo tempo, para a leitura dos poemas de Kabemba, aquilo que o mesmo Didi-Huberman defende, partindo do conceito de dialética benjaminiano, como um "remontar da história" como "remontagem" do contemporâneo. Algo como um testemunho da origem:

[...] na medida em que todo acontecimento histórico considerado para além da simples cronologia exige ser conhecido 'numa dupla ótica (...),por um lado, como uma restauração, uma restituição; por outro, como algo que é, por isso mesmo, inacabado, sempre aberto'; maneira de desmontar cada momento da história remontando, fora dos 'fatos constatados', àquilo que 'toca a sua pré e pós-história' (BENJAMIN, 1985, apud DIDI-HUBERMAN, 2017, p. 120-121).

Tal temporalidade histórica "remontada", sempre aberta e sustentada poeticamente pelo eu-lírico no enfrentamento do passado indígena, também sugere a presença da ancestralidade observada nos versos: "E na dança dos tempos / pajés e curacas / mantém a palavra / dos espíritos da mata / refúgio e morada / do povo cabeça-chata" (grifo nosso). Em "A queda do céu", observamos uma valorização análoga da potência das palavras dos espíritos no seguinte trecho:

As palavras estão coladas em nosso pensamento e surgem em nossos lábios, sem fim, assim que viramos espíritos. É por isso que somos capazes de revelá-la em seguida aos que nos escutam (...). Se eu não tivesse nenhuma casa dos espíritos (...) não teria nada a dizer (...) minha voz seria hesitante e quem me escutasse logo perceberia a ignorância e o medo entorpecendo minha boca (KOPENAWA; ALBERT, 2015, p. 466) grifo nosso.

Assim, a poetisa não deixará de ser uma indígena, pois isso está dentro dela, lhe pertence. Ao contrário disso, pondo-se ao lado de outros povos que vivenciam uma luta similar, de resistência e de subsistência, seu canto se faz guerreiro para que a importância dos seus pares seja reconhecida. 
Mister se faz reconhecer, ainda, que ao analisarmos um texto poético devemos considerar seus dois polos constitutivos: o plano da forma e o plano de conteúdo ou expressão. A partir desses polos buscamos explorar o poema "Ay Kakuyri Tama (Eu moro na cidade)" de Márcia Wayna Kambeba em sua dimensão compositiva das partes (análise da forma textual) e na dimensão do todo (a interpretação).

No que diz respeito ao plano da forma, o poema em questão mantém uma regularidade de estrofes com quatro versos, distribuídos heterometricamente ao longo do texto, pois não mantém uma regularidade métrica. A irregularidade métrica dos versos não tira, contudo, sua proximidade com o canto. É importante destacar aqui a força do canto, da oralidade como elemento fundamental a ser considerado no poema, pois remete à tradição dos povos indígenas, a sua ancestralidade, e o conflito de um indígena que na sociedade hodierna vê-se divido entre o passado e o presente, entre a sua comunidade e a cidade.

As quadras do poema, constituídas de versos que variam entre 8, 9, 7 e 10 sílabas poéticas nos remetem às canções românticas ou modernas. De acordo com Hênio Tavares, "a partir do romantismo a canção se revestiu de mais ampla liberdade formal e conceitual. Tornouse um poema simples, expressivo, e comportando os mais diversos assuntos" (2002, p. 274).

Enquadra-se, portanto, na categoria canção o poema "Ay Kakuyri Tama (Eu moro na cidade)" por se tratar de um texto lírico com uma densa carga de expressividade produzida pela escolha da composição em quadras, bem como pela ênfase dada aos versos com metrificação maior cuja extensão ganham uma entonação maior e reforçam a ideia do grito de liberdade, do apelo pela união como no verso "Se une aos Kambeba, aos Tembém, aos Guarani".

Como eixo agregador desses aspectos, observamos nos procedimentos referentes à dimensão interpretativa que a oralidade permeia as formas artístico- culturais dos povos indígenas brasileiros, pois sabemos que tais comunidades têm/tiveram na oralidade o papel de transmitir para as gerações futuras as tradições e costumes cultivados por eles, ou seja: a literatura indígena produz, em seus processos de entrecruzamentos e diálogos com a cultura do colonizador, cultura.

Nos dias atuais os estudiosos definem cultura como aquilo produzido pelo homem, o seu modo de agir e de pensar. Dessa forma, a cultura constitui-se em um processo dinâmico, assemelhando-se aos modos de vida do próprio indivíduo. Nesse caso, vemos que o poema de Márcia Kambeba escolhido como corpus para fomentar a discussão que propomos neste trabalho mantém um caráter cultural fortemente referenciador das expressões artísticas de seu povo. 
Vale ressaltar a importância dos povos indígenas para a cultura brasileira, porque identificamos a forte e marcada herança de costumes indígenas em várias regiões do Brasil, presente em vários setores da vida nacional, mas que parece passar "despercebida". E esse processo de incorporação do que era/é indígena na cultura nacional também deve ser alvo de debate e de reflexão.

\section{Considerações finais}

Este trabalho, pensado e realizado em conjunto, buscou problematizar algumas questões sobre a poesia indígena brasileira na atualidade e propor uma leitura crítico-analítica do poema “Ay Kakuyri Tama (Eu moro na cidade)", de autoria da indígena amazonense Márcia Wayna Kambeba.

Tal poema, conforme tentamos iluminar com os fragmentos postos em análise, nos mostra a presentificação da oralidade na poesia indígena atual, pois esta firma-se na ancestralidade, nos saberes dos mais velhos e nos ensinamentos aprendidos com as experiências vivenciadas coletivamente na aldeia e em contato com "sua gente". Nessa perspectiva, ao entrelaçar os saberes orais na forma expressiva do registro escrito, vimos no poema que a questão étnica emerge e incorpora as formas da literatura ocidental para "dar a ver" a cultura dos Kambeba.

Em síntese, é a memória que se coloca como fonte i/material ou como artefato para a poesia de Márcia Kambeba, reavivando os costumes e a ancestralidade de seu povo. Assim também se dá com a questão da identidade indígena. Essa última marcada pela territorialização da pessoa e não do lugar onde ela está momentaneamente, reforçando a ideia de que a cultura está em nós e, como tal, não é algo do qual podemos escapar.

Concluindo, podemos verificar que uma discussão em torno da literatura indígena brasileira atual pode nos revelar uma pluralidade de experiências estéticas desconhecidas por muitos de nós, possibilitando novas reflexões acerca do fazer literário, dos povos indígenas e das múltiplas possibilidades sobre as funções dos textos literários nas sociedades ocidentais e "tradicionais".

\section{Referências}

BENJAMIN, Walter. Obras Escolhidas II - Rua de mão única. São Paulo: Brasiliense, 2000, p. 239. 
BRANDÃO, Ana Paula [Org.]. Saberes e fazeres. Rio de Janeiro: Fundação Roberto Marinho, 2006.

CUCHE, Denys. A noção de cultura nas Ciências Sociais. 3. ed. Lisboa: Fim de Século Edições., 2006.

DIDI-HUBERMAN, Georges. Quando as imagens tomam posição: o olho da história, I. Trad. Berenice Paes Barroso Mourão. Belo Horizonte: Editora UFMG, 2017.

FOOT HARDMAN, Francisco. Morrer em Manaus: os avatares da memória em Milton Hatoum. Revista Tempo Brasileiro. Rio de Janeiro, n. 141, 2000, p.5-15.

GONÇALVES DIAS, Antônio. I - Juca-pirama /os Timbiras / Outros Poemas. São Paulo: Martin Claret, 2002.

KAMBEBA, Márcia Wayna. Poemas e crônicas: Ay Kakyri Tama = Eu moro na cidade. Manaus: Grafisa Gráfica e Editora, 2013.

KOPENAWA, Davi; BRUCE, Albert. A queda do céu. Cia das Letras, 2015.

LIMA, Ivaldo Marciano de França de. [et al]. África(s), índios e negros. Recife: Bagaço, 2016.

MUNDURUKU, Daniel. Literatura $x$ Literatura indígena: A produção de literatura dos indígenas brasileiros, $2016 . \quad$ Disponível em: http://danielmunduruku.blogspot.com/2016/02/literatura-X-literatura-indigena.html Acesso em 22/03/2019.

MOTA, Luiz Gonzaga. Análise crítica da narrativa. Brasília: Editora da UnB, 2013.

MUNRURULU, Daniel. Literatura Indígena. Overmundo. 30/11/2008. Disponível em: http://www.overmundo.com.br/imprime_overblog/literatura-indigena Acesso em 11/04/2019.

ORLANDI, Eni Puccinelli. As formas do silêncio: no movimento dos sentidos. Campinas/SP: Editora da UNICAMP, 1993.

ORLANDI, Eni Puccinelli. Terra à vista. Campinas: Cortez/Unicamp, 1990.

SILVA, Márcia Vieira da. Reterritorialização e identidade do povo Amágua- Kambeba na aldeia Tururucari- Uka. Dissertação de Mestrado do Curso de Pós-Graduação em Geografia da Universidade Federal do Amazonas - UFAM. Manaus, AM, 2012.

SOUZA, Kelly de. Tupi or not tupi? A identidade do Brasil pré-colonial na obra de autores índios e de escritores indigenistas. Revista da Cultura, n. 21, abril 2009. Disponível em http://www.revistadacultura.com.br:8090revista/RC21/index2.asp?page=capa Acesso: 24/03/2019.

POLLACK, Michael. Memórias e identidade social - Estudos históricos. Rio de Janeiro, vol. 5, n. 10, 1992, p. 204. 
Aceito em 23 de abril de 2020. 